Tropical Journal of Pharmaceutical Research April 2017; 16 (4): 787-793

ISSN: $1596-5996$ (print); 1596-9827 (electronic)

(C) Pharmacotherapy Group, Faculty of Pharmacy, University of Benin, Benin City, 300001 Nigeria.

All rights reserved.

Available online at http://www.tjpr.org

Original Research Article

http://dx.doi.org/10.4314/tjpr.v16i4.7

\title{
Sevoflurane anesthesia induces apoptosis and cell cycle arrest in NPC-039 nasopharyngeal cells
}

\author{
Yan Zhang ${ }^{1 *}$ and Hong Lin $^{2}$ \\ ${ }^{1}$ Department of Anesthesiology, Qilu Hospital of Shandong University, Jinan, Shandong 250012, ${ }^{2}$ Department of \\ Anesthesiology Shandong Qianfoshan Hospital, Jinan, Shandong 250013, China \\ *For correspondence: Email: yanzhang134@hotmail.com; Tel/Fax: 0086-531-82169114
}

\begin{abstract}
Purpose: To determine the effects of sevoflurane on NPC-039 nasopharyngeal carcinoma cells. Methods: WST-8 assays and flow cytometry with annexin V/PI staining were used to analyze the effects of sevoflurane on growth and induction of apoptotic changes in NPC-039 cells. Cell viability was performed on a microplate reader.

Results: Treatment of NPC-039 cells with $4-10 \mu \mathrm{M}$ sevoflurane significantly inhibited cell growth $(p<$ 0.005) with a median inhibitory concentration of $6 \mu \mathrm{M}$. NPC-039 cells incubated with sevoflurane showed prominent nuclear fragmentation and chromatin condensation. NPC-039 cells that exhibited apoptotic symptoms increased from 23.34 to $56.77 \%$ when duration of treatment was increased from 24 to $48 \mathrm{~h}$. Sevoflurane-treated cells also expressed increased levels of Bax and cleaved caspase-3. Reactive oxygen species formation was also higher in sevoflurane-treated NPC-039 cells than in control. Pre-treatment with Z-VAD-FMK followed by incubation with sevoflurane partly reduced the population of apoptotic NPC-039 cells compared with cells treated with sevoflurane alone. The proportion of cells in S- and G0/G1 phases decreased and increased, respectively, when sevoflurane concentration was increased from 2 to $10 \mu \mathrm{M}$. Incubating NPC-039 cells with sevoflurane also markedly reduced levels of cyclin-dependent kinases including p15 INK4B, cyclin D1, p16 INK4A, and CDK-6. In contrast, pretreatment with ZVAD-FMK followed by incubation with sevoflurane increased p15 INK4B levels.

Conclusion: Sevoflurane inhibits nasopharyngeal carcinoma cell growth, activating apoptosis and inducing cell cycle arrest, thus suggesting its therapeutic potential for the treatment of nasopharyngeal carcinoma.
\end{abstract}

Keywords: Sevoflurane, Nasopharyngeal carcinoma, Chromatin, Condensation

Tropical Journal of Pharmaceutical Research is indexed by Science Citation Index (SciSearch), Scopus, International Pharmaceutical Abstract, Chemical Abstracts, Embase, Index Copernicus, EBSCO, African Index Medicus, JournalSeek, Journal Citation Reports/Science Edition, Directory of Open Access Journals (DOAJ), African Journal Online, Bioline International, Open-J-Gate and Pharmacy Abstracts

\section{INTRODUCTION}

Nasopharyngeal carcinoma, which affects the head and neck tissues, has a high mortality rate; it is most common in Southeast Asia and south China [1]. According to a World Health Organization (WHO) report, more than $80 \%$ of the globally detected cases of nasopharyngeal carcinoma occur in China. Nasopharyngeal carcinoma is caused by different epidemiological, pathological, and virus-related mechanisms, and therefore differs from other common cancers of the head and neck [2].

At its early stage, the disease is currently treated using radiotherapy, but the relapse rate is very high, and the 5-year survival rate is very low [3]. In most cases, nasopharyngeal carcinoma undergoes metastasis to the neck lymph nodes, which worsens the prognosis [4]. The risk of 
treatment failure is nasopharyngeal carcinoma metastasizes to distant organs such as the lungs and liver [5]. Therefore, physicians are focusing on the screening and identification of novel therapeutic molecules that can inhibit nasopharyngeal carcinoma cell growth.

Sevoflurane is a commonly used anesthetic $[6,7]$. Sevoflurane treatment was found to induce apoptosis in alveolar lung carcinoma cells in vitro [8]. In addition, pretreating animals with sevoflurane prevented injury to various organs during ischemia-reperfusion [9, 10$]$. Furthermore, volatile anesthetic compounds have been shown to exert anti-inflammatory effects both in vitro and in vivo $[11,12]$.

Mechanistic studies have revealed that proinflammatory factors can suppress signal transduction pathways [13]. The induction of apoptosis via the intrinsic pathway is accompanied by reduced mitochondrial membrane potential, increased mitochondrial membrane permeability, and secretion of proapoptotic proteins from the mitochondria to the cytosol [14].

The in vitro production of reactive oxygen species (ROS) during oxidative stress also induces apoptosis via the mitochondrial pathway [15]. The present study aimed to evaluate the effects of sevoflurane on growth inhibition in nasopharyngeal carcinoma cells.

\section{EXPERIMENTAL}

\section{Chemicals and reagents}

Sevoflurane was purchased from Maruishi Pharmaceutical Co., Ltd, (Osaka, Japan). Annexin V was supplied by Becton Dickinson (Franklin Lakes, NJ, USA), and the caspase inhibitor Z-VAD was provided by Enzo Life Sciences (Plymouth Meeting, PA, USA). The disodium salt of 1,2-dihydroxy-3,5benzenedisulfonic acid in its monohydrated form (Tiron) was supplied by Dojindo Laboratories (Kumamoto, Japan).

\section{NPC-039 cell lines and culture}

The NPC-039 cell line was purchased from ScienCell Research Laboratories (Carlsbad, CA, USA) and was cultured in RPMI-1640 medium supplemented with $10 \%$ fetal calf serum, 100 $\mathrm{U} / \mathrm{mL}$ penicillin, and $100 \mathrm{mg} / \mathrm{mL}$ streptomycin. The cells were cultured at $37^{\circ} \mathrm{C}$ in an incubator in a humidified atmosphere of $5 \% \mathrm{CO}_{2}$ and $95 \%$ air.

\section{Analysis of cell growth}

NPC-039 cells were cultured in 96-well plates at a density of $2 \times 10^{5}$ cells per well. The cells were incubated with $2,4,6,8$, and $10 \mu \mathrm{M}$ sevoflurane or DMSO for $48 \mathrm{~h}$. Next, $10 \mu \mathrm{L}$ of the monosodium salt of WST-8 (Wako Chemical, Osaka, Japan) was added to each well, and the plates were incubated for $6 \mathrm{~h}$ in a humidified atmosphere of $5 \% \mathrm{CO}_{2}$ and $95 \%$ air at $37{ }^{\circ} \mathrm{C}$. The absorbance at $450 \mathrm{~nm}$ was then recorded using an iMark microplate reader (Bio-Rad, Hercules, CA, USA) to determine cell viability.

\section{Apoptosis analysis}

Sevoflurane-induced apoptosis in NPC-039 cells was analyzed using flow cytometry with annexin $\mathrm{V}$ and propidium iodide. NPC-039 cells were plated in 50-mm culture dishes at a density of $2 \times$ $10^{6}$ cells per dish, cultured for $24 \mathrm{~h}$, and then treated with $6 \mu \mathrm{M}$ sevoflurane with or without the caspase inhibitor Z-VAD (OMe)-FMK or DMSO alone. After incubation, the cells were collected, washed twice with ice-cold PBS, and treated with $1 \times$ binding buffer. Then, $10 \mu \mathrm{L}$ of annexin $\mathrm{V}$ and $\mathrm{PI}$ solution was added to each tube, and the cells were incubated in the dark for $20 \mathrm{~min}$. They were then treated with binding buffer and analyzed using a FACSCalibur flow cytometer and CellQuest software (both from Becton Dickinson).

\section{Measuring reactive oxygen species levels}

ROS levels in sevoflurane-treated NPC-039 cells were analyzed using flow cytometry. Briefly, NPC-039 cells were either untreated or pretreated with the ROS scavenger Tiron, and then incubated in six-well plates for $48 \mathrm{~h}$ with sevoflurane. Then, the cells were treated with 10 $\mu \mathrm{M}$ 5-(and-6)-chloromethyl-2',7'dichlorodihydro-fluorescein diacetate acetyl ester for $45 \mathrm{~min}$, and examined using a FACSCalibur flow cytometer and CellQuest software.

\section{Western blotting analysis}

NPC-039 cells were plated in 6-mm dishes at a density of $3 \times 10^{6}$ cells/dish in DMEM supplemented with $10 \%$ FBS. After culture for $48 \mathrm{~h}$, the cells were treated with sevoflurane for $48 \mathrm{~h}$ and harvested. Lysates were prepared using a NucleoSpin® RNA II kit (MachereyNagel, Düren, Germany) as per the manufacturer's protocol. Proteins were separated by electrophoresis on $10 \%$ sodium dodecyl sulfate-polyacrylamide gels, transferred to nitrocellulose membranes (Millipore, Bedford, MA, USA), and incubated with primary 
antibodies; $\beta$-actin was used as an endogenous control. The primary antibodies against $\beta$-actin, cyclin-dependent kinases-4 and -6, D1 p15INK4B, and p16-INK4A were obtained from Cell Signaling Technology (Danvers, MA, USA). Antibodies against $\mathrm{p}-\mathrm{MEK}$ and MEK were supplied by Sigma-Aldrich (St. Louis, MO, USA), and anti-caspase-3 and -Bax antibodies were purchased from Santa Cruz Biotechnology (Santa Cruz, CA, USA). After overnight incubation, the membranes were washed with PBS and incubated for $1 \mathrm{~h}$ with horseradish peroxidase-conjugated anti-rabbit IgG secondary antibodies (7074, Cell Signaling Technology). Protein-antibody complexes were visualized using an ECL plus kit (Amersham Biosciences, Hongkong) and a bio-image analyzer (Fuji Film, Tokyo, Japan).

\section{Statistical analysis}

The data are expressed as mean \pm standard deviation (SD), and data were analyzed using Student's $t$-tests. $P$-values $<0.005$ were taken to indicate statistical significance.

\section{RESULTS}

\section{Sevoflurane inhibits growth of NPC-039 cells}

WST-8 assays revealed that incubation with sevoflurane for $48 \mathrm{~h}$ inhibited the growth of NPC039 cells. Sevoflurane was added to cultures of NPC-039 cells at concentrations of 2, 4, 6, 8 and $10 \mu \mathrm{M}$; the growth inhibition was significant $(p<$ 0.005 ) after treatment with $\geq 4 \mu \mathrm{M}$ sevoflurane for $48 \mathrm{~h}$ (Figure 1). The median inhibitory concentration of sevoflurane on NPC-039 cells was $6 \mu \mathrm{M}$.

\section{Effect of sevoflurane treatment on NPC-039 cell apoptosis}

After incubation with sevoflurane, cells were analyzed for any alterations in their morphology. Cells treated with sevoflurane for $24 \mathrm{~h}$ exhibited prominent nuclear fragmentation and chromatin condensation (Figure 2). In addition, increasing the treatment duration from 24 to $48 \mathrm{~h}$ led to a marked increase in the percentage of apoptotic NPC-039 cells.

\section{Sevoflurane induced NPC-039 cell apoptosis}

The percentage of NPC-039 cells showing signs of apoptosis increased from 23.34 to $56.77 \%$ when the treatment time as increased from 24 to $48 \mathrm{~h}$ (Figure 3). The annexin V/PI-stained NPC039 cell population also increased as the treatment time increased from 24 to $48 \mathrm{~h}$ (Figure 3).

\section{Sevoflurane activates caspase-3 and elevates ROS levels in NPC-039 cells}

NPC-039 cells treated with $6 \mu \mathrm{M}$ sevoflurane for $48 \mathrm{~h}$ expressed increased levels of Bax and cleaved caspase-3 compared with untreated cells (Fig. 4A). Reactive oxygen species formation was also higher in sevoflurane-treated NPC-039 cells after $48 \mathrm{~h}$ of treatment (Figure 4B). Pre-treatment with Z-VAD-FMK (caspase inhibitor) for $30 \mathrm{~min}$ followed by $48 \mathrm{~h}$ incubation with $6 \mu \mathrm{M}$ sevoflurane reduced the population of apoptotic NPC-039 cells compared with cells treated with sevoflurane alone (Figure 4C). Moreover, pretreatment with Tiron (a ROS scavenger) followed by incubation with sevoflurane also reduced the size of the apoptotic NPC-039 cell population (Figure 4C).

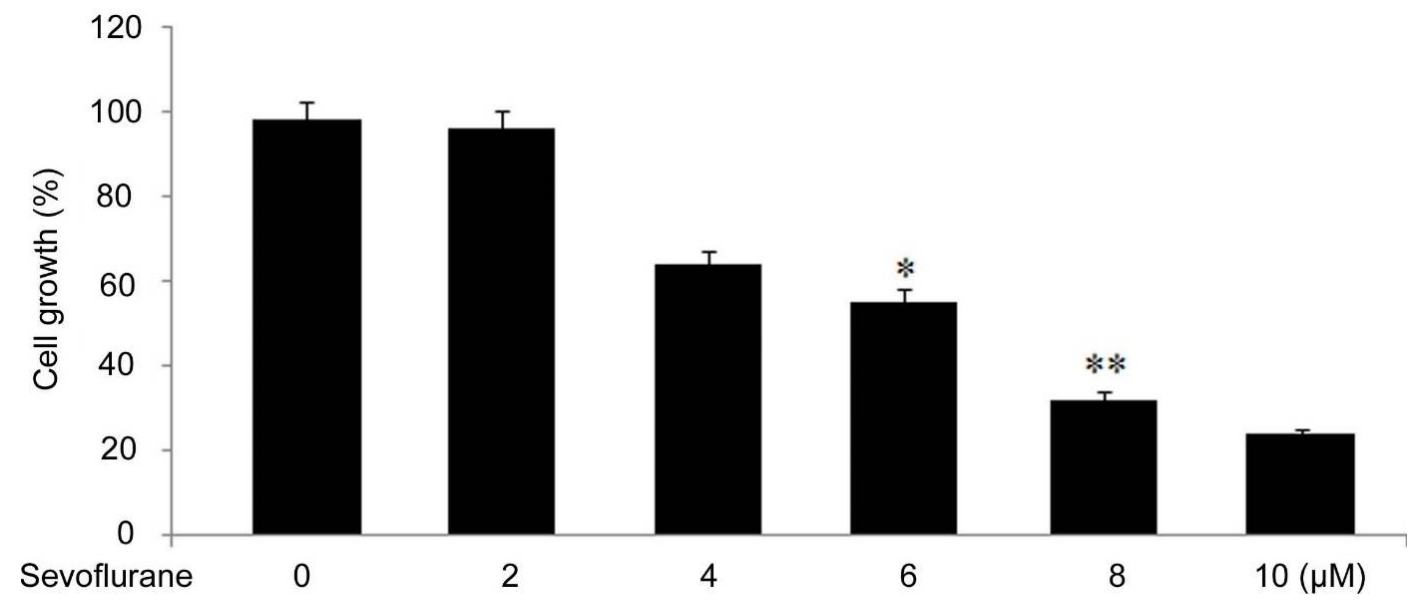

Figure 1: Sevoflurane inhibits the growth of NPC-039 cells. Cells were incubated with 2, 4, 6, 8 or $10 \mu \mathrm{M}$ of sevoflurane and then analyzed using WST-8 assays. Control cells were incubated with DMSO alone; ${ }^{* *} p<0.005$ vs. control cells 

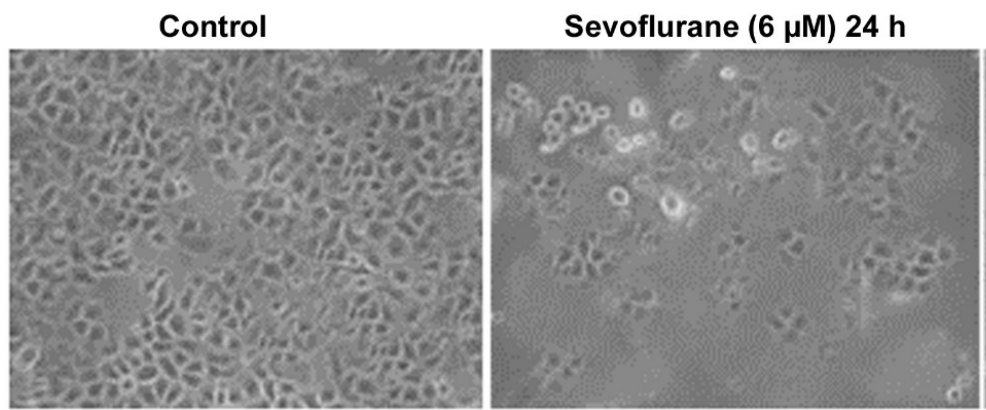

Sevoflurane $(6 \mu \mathrm{M}) 48 \mathrm{~h}$

Figure 2: Morphological alterations in NPC-039 cells following treatment with $6 \mu \mathrm{M}$ sevoflurane
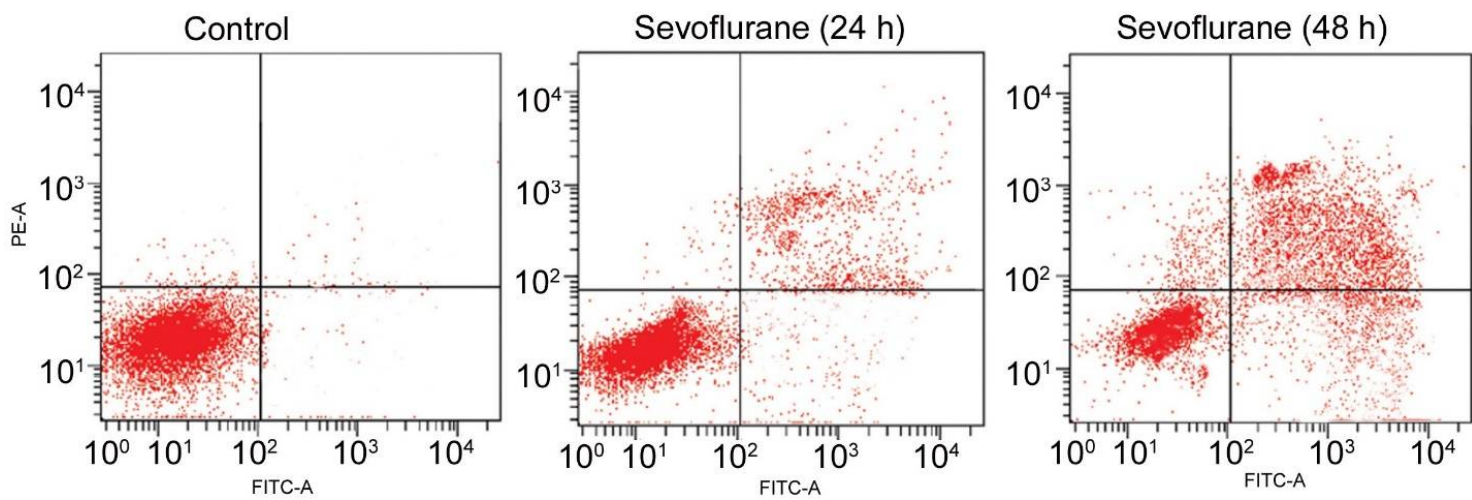

Figure 3: Sevoflurane induces apoptosis in NPC-039 cells. The cells were incubated with $6 \mu \mathrm{M}$ sevoflurane for 24 and $48 \mathrm{~h}$ and then analyzed by flow cytometry after staining with annexin V/PI. The induction of apoptosis was compared in sevoflurane-treated and control NPC-039 cells

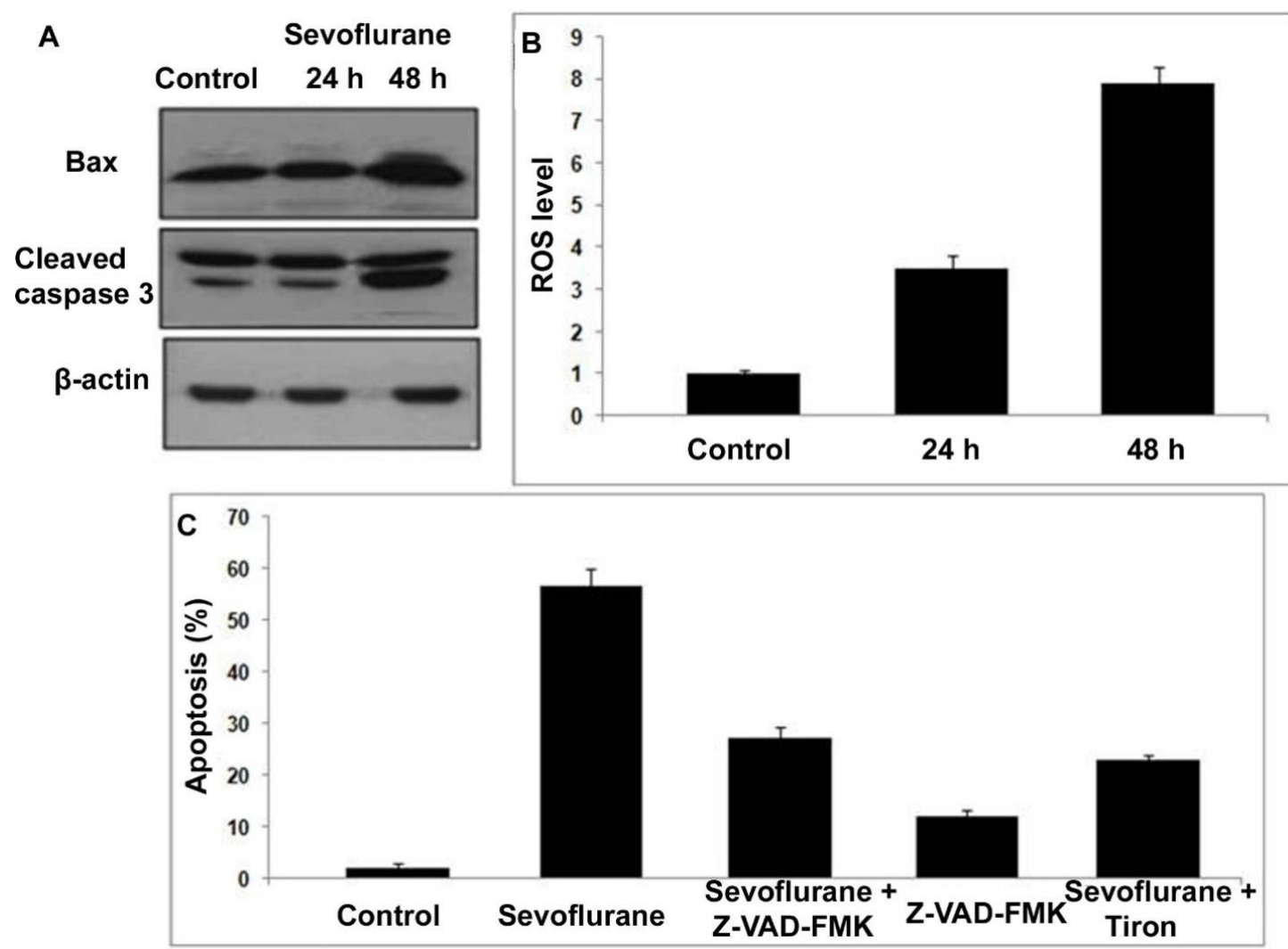

Figure 4: Sevoflurane treatment activates caspase-3 and Bax and induces ROS production; (A) Western blotting was performed after cells were treated with sevoflurane to determine the levels of caspase- 3 and Bax; (B) ROS production was analyzed in NPC-039 cells that had been incubated with $6 \mu \mathrm{M}$ sevoflurane with or without pretreatment with Z-VAD-FMK; (C) Apoptosis induction was analyzed in NPC-039 cells that had been incubated with $6 \mu \mathrm{M}$ sevoflurane with or without pretreatment with Tiron. Comparisons were made with control cells 


\section{Sevoflurane induces NPC-039 cell cycle arrest}

Incubating NPC-039 cells with sevoflurane for 48 $\mathrm{h}$ altered the size of the cell population in various phases of the cell cycle. The proportion of cells in the S-phase and G0/G1 phase was decreased and increased, respectively, by treatment with increasing concentrations of sevoflurane (2 to 10 $\mu \mathrm{M})$ for $48 \mathrm{~h}$ (Figure 5). The population of cells in the sub-G1 peak was increased significantly after sevoflurane treatment.

\section{Sevoflurane alters expression of CDK and its inhibitors}

In NPC-039 cells, incubation with sevoflurane for $48 \mathrm{~h}$ markedly reduced the levels of various cyclin-dependent kinases including p15 INK4B, cyclin D1, and CDK-6 (Figure 6). In contrast, pretreating NPC-039 cells with ZVAD-FMK followed by incubation with sevoflurane for $48 \mathrm{~h}$ increased the levels of p15 INK4B (Figure 6).

\section{DISCUSSION}

In the present study, the inhibitory effects of sevoflurane on NPC-039 cell growth were assessed in vitro. The results revealed that sevoflurane significantly inhibited the growth of NPC-039 nasopharyngeal carcinoma cells.

Previous studies demonstrated that sevoflurane treatment induced apoptosis in vitro in alveolar lung carcinoma cells [8]. In the current study, the addition of sevoflurane to NPC-039 cells inhibited their growth. Further examination of the cells revealed that sevoflurane treatment led to prominent nuclear fragmentation and chromatin condensation. The mechanism by which sevoflurane inhibited NPC-039 cell growth was also investigated. Flow cytometric analysis of NPC-039 cells revealed an increase in the percentage of cells with apoptotic characteristics from 23.34 to $56.7 \%$ when the treatment duration was increased from 24 to $48 \mathrm{~h}$.

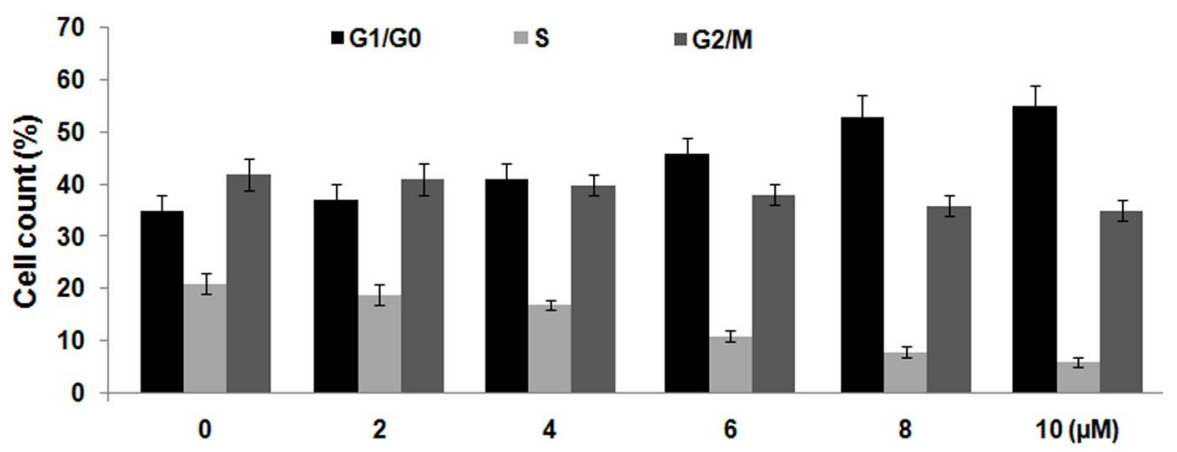

Figure 5: Sevoflurane alters the proportion of NPC-039 cells in different phases of the cell cycle. Sevoflurane (2 to $10 \mu \mathrm{M}$ ) was added to cultures of NPC-039 cells and incubated for $48 \mathrm{~h}$. Flow cytometry was then used to analyze the proportion of cells in various phases of the cell cycle

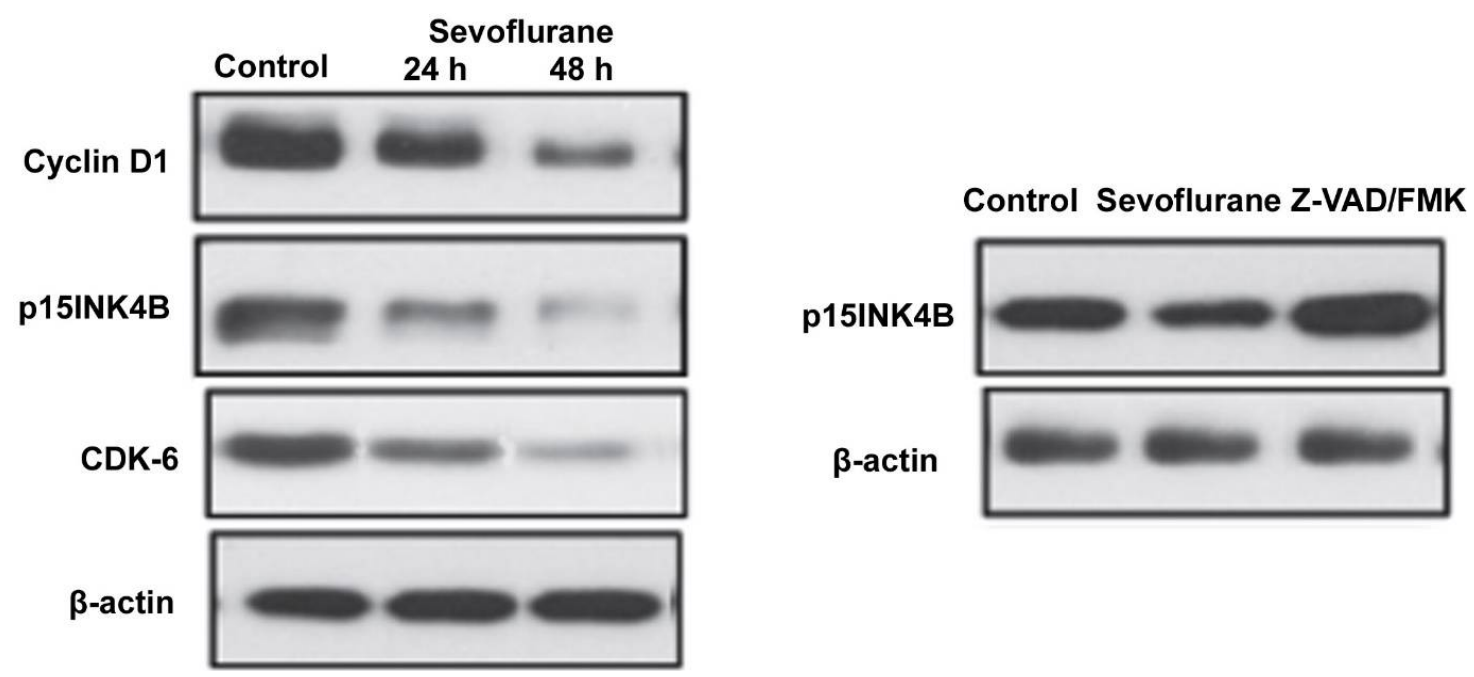

Figure 6: Effects of sevoflurane on the levels of cyclin-dependent kinase and its inhibitors. Western blotting was used to determine the expression of p15 INK4B, cyclin D1, and CDK-6 in NPC-039 cells after $48 \mathrm{~h}$ of treatment with sevoflurane. The levels of p15 INK4B were also analyzed after cells were pretreated with ZVAD-FMK 
The size of the annexin V/PI-stained NPC-039 cell population also increased when the treatment time was increased from 24 to $48 \mathrm{~h}$.

The factors that contribute to the anti-cancer properties of chemotherapeutic agents include increasing the levels of ROS and p27 [16, 17]. The current results showed that NPC-039 cells treated with sevoflurane expressed higher levels of ROS. Sevoflurane also increased the concentrations of Bax and cleaved caspase-3 compared with untreated cells. However, pretreatment with the caspase inhibitor Z-VAD-FMK followed by exposure to sevoflurane partly reduced the population of apoptotic NPC-039 cells compared with sevoflurane treatment alone. In addition, pretreatment with the ROS scavenger Tiron followed by incubation with sevoflurane also reduced the apoptotic NPC-039 cell population. Thus, the present study demonstrated that sevoflurane inhibited NPC039 cell growth via two pathways. The first involves the induction of apoptosis via ROS generation and increased caspase- 3 and Bax levels. The second pathway involves inducing cell cycle arrest via the increased expression of CDK inhibitors and decreased levels of CDKs.

\section{CONCLUSION}

The ability of sevoflurane to inhibit nasopharyngeal carcinoma cell growth by activating apoptosis and arresting the cell cycle indicates that it is a potent chemotherapeutic agent that could be an effective treatment for nasopharyngeal carcinoma.

\section{DECLARATIONS}

\section{Acknowledgement}

None declared

\section{Conflict of Interest}

No conflict of interest associated with this work.

\section{Contribution of Authors}

The authors declare that this work was done by the authors named in this article and all liabilities pertaining to claims relating to the content of this article will be borne by them.

\section{Open Access}

This is an Open Access article that uses a funding model which does not charge readers or their institutions for access and distributed under the terms of the Creative Commons Attribution License (http://creativecommons.org/licenses/by/ 4.0) and the Budapest Open Access Initiative (http://www.budapestopenaccessinitiative.org/rea d), which permit unrestricted use, distribution, and reproduction in any medium, provided the original work is properly credited.

\section{REFERENCES}

1. Chang ET, Adami HO. The enigmatic epidemiology of nasopharyngeal carcinoma. Cancer Epidemiol Biomarkers Prev 2006; 15: 1765-1777.

2. Guigay J. Advances in nasopharyngeal carcinoma. Curr Opin Oncol 2008; 20: 264-269.

3. Wei WI, Sham JS. Nasopharyngeal carcinoma. Lancet 2005; 365: 2041-2054.

4. Chua DT, Sham JS, Wei WI, Ho WK, Au GK. The predictive value of the 1997 American Joint Committee on cancer stage classification in determining failure patterns in nasopharyngeal carcinoma. Cancer 2001; 92: 2845-2855.

5. Cheng SH, Jian JJ, Tsai SY, Chan KY, Yen LK, Chu NM, Tan TD, Tsou MH, Huang AT. Prognostic features and treatment outcome in locoregionally advanced nasopharyngeal carcinoma following concurrent chemotherapy and radiotherapy. Int J Radiat Oncol Biol Phys 1998; 41: 755-762.

6. Chandler JR, Myers D, Mehta D, Whyte E, Groberman MK, Montgomery CJ, Ansermino JM. Emergence delirium in children: a randomized trial to compare total intravenous anesthesia with propofol and remifentanil to inhalational sevoflurane anesthesia. Paediatr Anaesth 2013; 23: 309-315.

7. Bi SS, Deng CH, Zhou TY, Guan Z, Li L, Li HQ, Zhang $L P$, Yang $L, L u W$. Remifentanil-sevoflurane interaction models of circulatory response to laryngoscopy and circulatory depression. Br J Anaesth 2013; 110: 729740.

8. Guui-Hua W, Juan Z, Da-Qing L, Zhuo L, Jing Y, NanFu L, Yan G. The common anesthetic, sevoflurane, induces apoptosis in A549 lung alveolar epithelial cells. Mol Med Rep 2014; 9: 197-203.

9. Oka M, Hirazawa K, Yamamoto K, lizuka N, Hazama S, Suzuki T, Kobayashi N. Induction of Fas-mediated apoptosis on circulating lymphocytes by surgical stress. Ann Surg 1996; 223: 434-440.

10. Sasajima K, Inokuchi K, Onda M, Miyashita M, Okawa KI, Matsutani T, Takubo K: Detection of $T$ cell apoptosis after major operations. Eur J Surg 1999; 165: 1020-1023.

11. Giraud $O$, Seince PF, Rolland C, Lecon-Malas $V$, Desmonts JM, Aubier M, Dehoux M. Halothane reduces the early lipopolysaccharide-induced lung inflammation in mechanically ventilated rats. Am J Respir Crit Care Med 2000; 162: 2278-2286. 
12. Helmy SA, Al-Attiyah RJ. The effect of halothane and isoflurane on plasma cytokine levels. Anaesthesia 2000; 55: 904-910.

13. De Rossi LW, Brueckmann M, Rex S, Barderschneider $M$, Buhre $W$, Rossaint $R$. Xenon and isoflurane differentially modulate lipopolysaccharide-induced activation of the nuclear transcription factor $K B$ and production of tumor necrosis factor-alpha and interleukin-6 in monocytes. Anesth Analg 2004; 98: 1007-1012.

14. Ralph SJ, Rodríguez-Enríquez S, Neuzil J, MorenoSánchez $R$. Bioenergetic pathways in tumor mitochondria as targets for cancer therapy and the importance of the ROS-induced apoptotic trigger. Mol Aspects Med 2010; 31: 29-59.

15. Telser J. Free radicals and antioxidants in normal physiological functions and human disease. Int $\mathrm{J}$ Biochem Cell Biol2007; 39: 44-84.

16. Akamatsu H, Komura J, Asada $Y$, Niwa Y. Effects of cepharanthin on neutrophil chemotaxis, phagocytosis, and reactive oxygen species generation. $J$ Dermatol 1991; 18: 643-648.

17. Harada K, Supriatno, Yamamoto $S$, Kawaguchi $S$, Yoshida H, Sato M. Cepharanthine exerts antitumor activity on oral squamous cell carcinoma cell lines by induction of p27Kip1. Anticancer Res 2003; 23: 14411448. 